\title{
Presença do vírus da artrite-encefalite caprina na forma de partículas virais livres infecciosas no líquido seminal de caprinos soropositivos
}

\author{
Detection of caprine arthritis-encephalitis virus as cell-free virus in \\ semen from seropositive bucks.
}

\author{
Carlos Eurico Pires Ferreira Travassos, ${ }^{*}$ Angela Gonçalves da Silva, ${ }^{*}$ Gerard Perrin **
}

\begin{abstract}
Resumo
Amostras de líquido seminal livre de células de dez caprinos soropositivos foram analisadas quanto à presença do vírus da artrite-encefalite caprina (CAEV) através de cultura e técnicas de amplificação enzimática (PCR). A presença do CAEV foi detectada por PCR em seis de dez no final de oito semanas de cultivo. Entre as seis amostras PCR positivas, quatro demonstraram a formação de efeito citopático (sincício). Esses resultados sugerem a possibilidade do CAEV ser transmitido por via sexual.
\end{abstract}

Palavras-chave: vírus da artrite-encefalite caprina; polymerase chain reaction; transmissão.

\section{Introdução}

O vírus da artrite-encefalite caprina (CAEV), um lentivírus, é a causa de perdas econômicas importantes para a indústria caprina. Em razão de não haver, infelizmente, alguma perspectiva próxima em matéria de vacinação, os programas de controle da doença tem-se baseado na prevenção da transmissão através do colostro e ou do leite. Entretanto, apesar dessas medidas terem diminuído a prevalência da doença em planteis com vistas à erradicação (Adams et al., 1983.; East et al., 1987.; East et al., 1993.; Mackenzie et al., 1987), alguns estudos epidemiológicos (East et al., 1987; Rowe et al., 1991) têm demonstrado a ocorrência de recontaminações, algumas vezes maciças, totalmente inexplicáveis. Essas observações nos fazem pensar que outras vias de contaminação, em adição ao colostro e leite, podem ser importantes em certas condições. Apesar de vários trabalhos terem sido realizados com vistas a precisar os modos de transmissão do vírus, restam, ainda hoje, algumas dúvidas que precisam ser esclarecidas, como, por exemplo, a transmissão sexual que ainda não foi bem esclarecida. Recentemente, em um trabalho anterior, foi detectada, através da técnica double nested-PCR, a presença do CAEV-DNA e RNA no sêmen de animais soropositivos (dados pessoais). Entretanto, essa técnica detecta a presença do vírus independentemente de sua capacidade de causar infecção. Sabendo que o CAEV pode ser encontrado na forma de partículas virais livres no líquido seminal de animais infectados por esse vírus, nosso trabaIho teve como objetivo verificar se essas partículas são infecciosas. Para isso, inoculamos o líquido seminal em cultura de células primárias de membrana sinovial, que foram posteriormente analisadas por PCR.

\section{Material e métodos}

\section{Animais}

Foram utilizados, nesse experimento, dez caprinos machos soropositivos, nos quais já tinha sido detectada a presença do CAEV nos respectivos sêmens, em um trabalho anterior. Paralelamente, foram coletadas amostras de dois caprinos machos soronegativos que foram utilizados como controles negativos.

Foram coletadas amostras de sêmen e de sangue.

\section{Sêmen}

Todas as amostras de sêmen, onde o volume variava de 1 a $2 \mathrm{ml}$ foram coletadas através de uma vagina artificial e processadas no laboratório no máximo 4 horas após a coleta. Após centrifugação a $800 \times \mathrm{g}$ por $10 \mathrm{~min}$, o sobrenadante (LS) foi coletado, clarificado a $5000 \times \mathrm{g}$ por $10 \mathrm{~min}$ a $4^{\circ} \mathrm{C}$, e em seguida, concentrado por ultracentrifugação a $20000 \times$ g por 2 horas a $4^{\circ} \mathrm{C}$ sobre gradiente de sacarose a $20 \%$. Após a ultracentrifugação,

\footnotetext{
*Instituto de Microbiologia Prof. Paulo de Góes - CCS - bloco I - Universidade Federal do Rio de Janeiro - Ilha do Fundão; Rio de Janeiro ; Brasil.CEP: 21 941-590; fax: 021560 8344; e-mail: imadags@microbio.ufrj.br

${ }^{\star *}$ CNEVA Station Régionale de Pathologie Caprine- 60 rue de pied de fond 79012 NIORT- France; BP: 3081; e-mail: srpc@interpc.fr
} 
o sobrenadante foi descartado, o pellet ressuspenso em 4 $\mathrm{ml}$ de meio de cultura (HMEM) adicionado de $8 \%$ de DMSO, e conservado $\mathrm{a}-80^{\circ} \mathrm{C}$ antes de serem inoculados em culturas de células de membrana sinovial caprina, para isolamento viral e posterior PCR. O pellet obtido após a primeira centrifugação (CMNE e SPZ), foi estocado a $-80^{\circ} \mathrm{C}$.

\section{Sangue}

As amostras de sangue, coletadas em tubos venoject de $10 \mathrm{ml}$ contendo EDTA, foram obtidas por punção venosa na jugular. Paralelamente, foram coletados $5 \mathrm{ml}$ de sangue para a obtenção de soro. Uma fração de células mononucleares foi obtida por centrifugação a $700 \times$ g por 20 min. sobre igual volume de gradiente de densidade (Histopack 1077Sigma). Após a centrifugação, as células mononucleares localizadas na interfase foram coletadas, lavadas $2 x$ com PBS pH 7,2 a $700 \times$ g por 5 min. e estocadas (pellet seco) a $-80^{\circ} \mathrm{C}$ para posterior extração do DNA.

\section{Culturas celulares}

As células de membrana sinovial de caprino foram obtidas de cabritos privados de colostro, todos provenientes de criações oficialmente indenes para o CAEV, pelo menos a 5 anos. As células foram cultivadas em monocamadas em meio de cultura HMEM (Minimum Essential Medium), suplementado com $10 \%$ de soro fetal bovino inativado. Após as inoculações das frações de LS processadas anteriormente, as culturas inoculadas foram cultivadas com meio nutritivo (HMEM) adicionado com $4 \%$ de soro fetal bovino. As subculturas foram realizadas a cada semana. A partir do momento em que foi observado o aparecimento dos efeitos citopáticos ou no final de oito semanas, as culturas inoculadas e não inoculadas (controle negativo) foram raspadas, lavadas $2 x$ a $700 \times \mathrm{g}$ com PBS pH 7,2 e estocadas a $-80^{\circ} \mathrm{C}$ para posterior extração do DNA.

\section{Extração e amplificação do DNA}

Todas as extrações foram realizadas através de um kit comercial (Isoquick-Microprobe), conforme as instruções do fabricante. Após a lise e precipitação (etanol), o DNA foi dissolvido em tampão TE $0,1 \times$ (Tris $\mathrm{HCl}$ pH 8,0 1mM; EDTA $0,1 \mathrm{mM}$ ) e quantificado ao espectrofotômetro. Os fragmentos de DNA de $175 \mathrm{pb}$ e $350 \mathrm{pb}$, correspondendo respectivamente às regiões pol e env, foram co-amplificados pela técnica nested-PCR. Os primers externos utilizados foram: 5374 (5'-ACAGAAGAGAAATTAAAAGG-3', pb 2236-2255), e 5376 (5'-ATCATCCATATATATGCCAAATTG3', bp 2712-2689 ) para a região pol, e 99001(5'AGGTAAGTATAAACCCCAGGTAAG-3', pb6122-6145) e 5086 (5'-ATTCTTATCTTTTATTCCCCCATA-3', pb69626939) para a região env. Os primers internos utilizados foram: 5375 (5'-CAGGGAAGTGGAGAATGTTAAT-3', pb 2357-2378), e 5377 (5'-GGTATAGTAAAATATGCATCTCCT3', pb 2510-2487), para a região pol, e 99006 (5'CATTGCCCTTTATGGCAAATGG-3', pb 6471-6492) e 99008
(5'-GATGTTCATAAAGGCCATGCTCTC-3', pb 6812-6789), para a região env. As posições dos primers utilizados para amplificar os fragmentos subgenômico do vírus correspondem à seqüência da cepa Cork do CAEV (Saltarelli et al., 1990). As reações de amplificação para ambos os primers foram realizadas em um único tubo (double nested - PCR) em aparelho GeneAmp PCR System 9600 - Perkin-Elmer. Durante o primeiro ciclo de amplificação (PCR), $1 \mu \mathrm{g}$ de DNA genômico foi amplificado em $50 \mu$ l de solução contendo $10 \mathrm{mM}$ Tris $\mathrm{HCl}$ pH 8,3; $50 \mathrm{mM} \mathrm{KCl} ; 2 \mathrm{mM} \mathrm{MgCl} ; 0,001 \%$ gelatina; $200 \mu \mathrm{M}$ de cada dNTP; 100 ng de cada primer externo; e 1 unidade de taq polimerase - Ampli Taq PerkinElmer. No segundo ciclo de amplificação, $5 \mu l$ da reação do primeiro ciclo foi novamente amplificado com a mesma solução reacional contendo dessa vez 100 ng de cada primer, interno. As reações de amplificação foram realizadas de acordo com o programa: primeiro ciclo, desnaturação por 5 minutos a $95^{\circ} \mathrm{C}$, seguido de uma série de 35 ciclos sucessivos compreendido por uma nova fase de desnaturação de 40 segundos a $92^{\circ} \mathrm{C}$, uma fase de hibridação de 50 segundos a $56^{\circ} \mathrm{C}$, e uma fase de extensão de 1 minuto a $72^{\circ} \mathrm{C}$. A série de ciclos foi terminada por uma fase de extensão final de 5 minutos a $72^{\circ} \mathrm{C}$. O segundo ciclo (nested-PCR) foi composto por 35 ciclos sucessivos compreendido por uma fase de desnaturação de 40 segundos a $92^{\circ} \mathrm{C}$, uma fase de hibridação de 40 segundos a $60^{\circ} \mathrm{C}$, e uma fase de extensão de 40 segundos a $72^{\circ} \mathrm{C}$, seguida de uma fase de extensão final de 5 minutos a $72^{\circ} \mathrm{C}$. Apropriados controles negativos e positivos foram colocados em paralelo com as amostras. Os produtos amplificados $(10 \mu \mathrm{l})$ foram separados por eletroforese em gel de agarose a $3 \%$, juntamente com marcadores de DNA. Os géis foram tratados com Bret (brometo de etídio), e visualizados por transiluminação com luz ultravioleta.

\section{Resultados}

Os resultados das análises realizadas a partir das amostras de sangue (células mononucleares) e líquido seminal (LS) estão apresentadas na Tabela 1. Após um período máximo pós-inoculação de oito semanas, foi detectada por double nested-PCR, a presença do CAEV em seis de dez culturas inoculadas com LS previamente tratados, obtidos dos animais soropositivos. Entretanto, apenas nas amostras dos animais 5, 6, 15, e 31 foi observada a formação de sincícios após 10,14, 22, e 48 dias pós-inoculação, respectivamente. Nas amostras dos animais 1 e 10, apesar de terem sido PCR positivo no final das oito semanas, não foi observada a formação de sincício nas respectivas culturas. As culturas dos animais 4,12,13, e 50, foram negativas.

Todas as amostras de células mononucleares do sangue dos dez animais soropositivos foram PCR positivo.

Nenhuma reação positiva foi observada entre os dois soronegativos. Da mesma forma, nenhuma reação positiva foi observada nos controles de células (culturas não inoculadas). 
Tabela 1: Análise das amostras de líquido seminal e células mononucleares do sangue de 12 caprinos (10 soropositivos, animais no 1, 4, 5, 6, 10, 12, 13, 15,31 e 50, e dois soronegativos $L 190$ e L510) para presença do CAEV pela técnica double nested PCR. Os animais foram considerados positivos $(+)$, quando ao menos uma das duas seqüências-alvo ( $p o / 175 \mathrm{pb}$ e env $350 \mathrm{pb}$ ) foi amplificada em cada fração analisada. Nesse caso, a seqüência amplificada está indicada. As amostras de líquido seminal foram inoculadas em cultura primária de células de membrana sinovial caprina e analisadas posteriormente por $P C R$ como descrito no texto.

\begin{tabular}{cccc}
\hline Animais & LS & CMS & Sincício (dpi) \\
\hline 1 & + env & + env & - \\
4 & - & + pol/env & - \\
5 & + pol/env & + pol/env & 10 \\
6 & + pol/env & + env & 14 \\
10 & + pol & + pol/env & - \\
12 & - & + env & - \\
13 & - & + pol/env & - \\
15 & + env & + pol/env & 22 \\
31 & + env & + pol/env & 48 \\
50 & - & + pol & - \\
L190 & - & - & - \\
L510 & - & - & -
\end{tabular}

\section{Discussão}

O uso da técnica PCR tem-se mostrado o mais sensivel método utilizado para a detecção de lentivírus no sangue e sêmen de humanos e animais (Van Voorhis et al., 1991; Mermin et al., 1991; Rimstad \& Ueland., 1992; Hamed et al., 1993; Barlough et al.,1994; Jordan et al., 1995; Nash et al.,1995). Entretanto, essa técnica detecta a presença viral independentemente da sua capacidade de causar infecção. Por exemplo, um resultado PCR positivo pode re- presentar a detecção de partículas virais defectivas ou incompletas em adição às partículas competentes para replicação. Isso explica a alta taxa de detecção observada em estudos nos quais foi utilizada essa técnica em comparação com técnicas de cultura viral (Krieger et al., 1991; Mermin et al., 1991; Hamed et al., 1993).

Nesse estudo, a inoculação do líquido seminal em culturas primárias de células de membranas de tecido sinovial caprino, induziu a formação de efeito citopático (sincício) em quatro de seis amostras que apresentaram um resultado PCR positivo no final de oito semanas de cultivo. Esses resultados, além de confirmarem que o CAEV pode estar presente na forma de partículas virais livres no líquido seminal de caprinos machos soropositivos, demonstram que essas partículas são infecciosas. Nas outras duas amostras, as quais foram PCR positivas, não ocorreu efeito citopático nas respectivas culturas, provavelmente devido ao fato de que a quantidade de células infectadas era muito baixa para que pudesse ser observada a formação de efeito citopático, porém, em número suficiente para permitir a detecção por double nested-PCR (a técnica é capaz de detectar 1 célula infectada em 10000). Além disso, para confirmar que o sinal obtido foi resultado da infecção das culturas e não de eventuais células mononucleares ou outras células existentes no sêmen (células epiteliais, espermatozóides, células germinais imaturas, etc.) que porventura pudessem permanecer no LS, todas as amostras foram centrifugadas e em seguida ultracentrifugadas em gradiente de sacarose a $20 \%$ para remover todo material celular. Para confirmar esses resultados, cada amostra foi analisada duas vezes por PCR e apresentaram resultados idênticos, o que exclui teoricamente uma possível contaminação entre as amostras de DNA durante as manipulações.

Em resumo, nosso trabalho demonstrou in vitro a presença do CAEV na forma de partículas virais livres infecciosas no LS de caprinos infectados, através da inoculação desse material em cultura primária de células de membrana sinovial caprina. Embora a transmissão sexual do CAEV não tenha sido até hoje demostrada in vivo, esses resultados demonstram que existe um risco em potencial de ocorrer uma transmissão por essa via.

\begin{abstract}
Cell-free seminal fluids of 10 seropositive bucks were evaluated for the presence of caprine arthritis-encephalitis virus (CAEV) using cell culture and polymerase chain reaction (PCR). CAEV was detected by double nested PCR after 8 weeks of cultivation. Amongst the 6 PCR positive samples, 4 samples demonstrated productive infection determined by syncytium formation. These results suggest the possibility of sexual transmission of CAEV.
\end{abstract}

Keywords: caprine arthritis-encephalitis virus; polymerase chain reaction; semen transmission. 


\section{Referências bibliográficas}

ADAMS, D. S., KLEVJER-ANDERSON, P., CARLSON, J. L., MCGUIRE, T. C. and GORHAM, J. R.,. Transmission and control of caprine arthritis-encephalitis. Am. J. Vet. Res., n. 44 , p. $1670-1675,1983$.

BARLOUGH, J., EAST, N., ROWE, J. D., VAN HOOSEAR, K., DEROCK, E., BIGORNIA, L. and RIMSTAD, E. Doublenested polymerase chain reaction for detection of caprine arthritis-encephalitis virus proviral DNA in blood, milk and tissues of infected goats. J. Virol Methods, n. 50, p. 101114, 1994.

EAST, N. E., ROWER, J. D., DAHLBERG, J. E., THEILEN, G. H. and PEDERSEN, N. C. Modes of transmission of caprine arthritis-encephalitis virus infection. Small Ruminant Res., n. 10, p. 251-262, 1993.

EAST, N. E., ROWER, J.D., MADEWELL, B. R. andFLOYD, K. Serologic prevalence of caprine arthritis- encephalitis virus in Califomia goat dairies. J. Am. Vet. Assoc., n. 190, p. 182-186, 1987.

HAMED, K. A., WINTERS, M. A., HOLODNIY, M., KATZENSTEIN, D. A., and MERIGAN, T.C. Detection of human immunodeficiency virus type 1 in semen: effects of disease stage and nucleoside therapy. J. Infect. Dis., n. 167, p. 798802, 1993.

JORDAN, H. L., HOWARD, J., TOMPKINS, W. A. and STOSKOPF, S. K. Detection of feline immunodeficiency virus in semen from seropositive domestic cats. J. Virol., n. 69, p. $7328-7333,1995$.

KRIEGER, J. N., COOMBS, R. W., COLLIER, A. C., ROSS, S. O., CHALOUPA, K., CUMMINGS, D. K., MURPHY, V. L. and COREY, $L$. Recovery of human immunodeficiency virus type 1 from semen: minimal impact of stage of infection and current antiviral chemotherapy. J. infect. Dis., n. 163, p. 386-388, 1991.

MACKENZIE, R. W., OLIVIER, R. E. and ROONEY, J. P. A successful attempt to raise goat kids free of infection with caprine arthritis-encephalitis virus in an endemically infected goat herd. NZ Vet. J., n. 35, p. 184-186, 1987.

MERMIN, J. H., HOLODNIY, M., KATZENSTEIN, D. A. and MERIGAN, T. C. Detection of human immunodeficiency virus DNA and RNA in semen by the polymerase chain reaction. J. Infect. Dis., n. 164, p. 769-772, 1991.

NASH, J. W., HANSON, L. A. and ST. CYR COATS. Bovine immunodeficiency virus in stud bull semen. Am. J. Vet. Res., n. 56, p. 760-763, 1995.

RIMSTAD, E. and UELAND, K. Detection of feline immunodeficiency virus by a nested polymerase chain reaction. J. Virol. Methods, n. 36, p. 239-248, 1992.

ROWER, J. D., EAST, N. E., THURMOND, M. C. and FRANTI, C. E. Risk factors associated with caprine arthritis-encephalitis virus infection in goats on California dairies. Am. J. Vet Res., n. 52, p. 510-514, 1991.

SALTARELLI, M., QUÉRAT, G., KONINGS, D. A. M., VIGNE, R. and CLEMENTS, J. E. Nucleotide sequence and transcriptional analysis of molecular clones of CAEV which generate infectious virus. Virology, n. 179, p. 347-364, 1990.

VAN VOORHIS, B. J., MARTINEZ, A., MAYER, K. and ANDERSON, D. J. Detection of human immunodeficiency virus type 1 in semen from seropositive men using culture and polymerase chain reaction deoxyribonucleic acid amplification technique. Fertil. Steril., n. 55, p. 588-594, 1991.

\section{H HEXÁGONO}

Química e Equipamentos para Laboratórios

\section{Distribuidor Merck}

Rua Souza Barros, n 560 - Engenho Novo

20961-150 - Rio de Janeiro, RJ
Tel.: (021) 501-4536

Fax: (021) 501-3723 